in vivo $30: 769-776(2016)$

doi:10.21873/invivo.10993

\title{
BUBR1 Insufficiency in Mice Increases their Sensitivity to Oxidative Stress
}

\author{
DAISUKE MATSUDA ${ }^{1}$, TAKUYA MATSUMOTO ${ }^{1}$, KENICHI HONMA $^{1}$, \\ AYAE IKAWA-YOSHIDA ${ }^{1}$, MITSUHO ONIMARU ${ }^{2}$, TADASHI FURUYAMA ${ }^{1}$, \\ YOSHIMICHI NAKATSU ${ }^{3}$, TERUHISA TSUZUKI ${ }^{3}$ and YOSHIHIKO MAEHARA ${ }^{1}$ \\ ${ }^{1}$ Department of Surgery and Science, Graduate School of Medical Sciences, Kyushu University, Fukuoka, Japan; \\ ${ }^{2}$ Division of Pathophysiological and Experimental Pathology, Department of Pathology, \\ Graduate School of Medical Sciences, Kyushu University, Fukuoka, Japan; \\ ${ }^{3}$ Department of Medical Biophysics and Radiation Biology, \\ Graduate School of Medical Sciences, Kyushu University, Fukuoka, Japan
}

\begin{abstract}
Background/Aim: Budding uninhibited by benzimidazole-related 1 (BUBR1) plays an important role in the spindle assembly checkpoint to prevent chromosome missegregation and aneuploidy during mitosis. We previously generated mutant mice that express BUBR1 at only $20 \%$ of the normal level (BubRI ${ }^{L / L}$ mice). Here, we examined the effect of low BUBRI expression on oxidative stress-induced carcinogenesis in mice. Materials and Methods: We orally administered either a potassium bromate $\left(\mathrm{KBrO}_{3}\right)$ solution

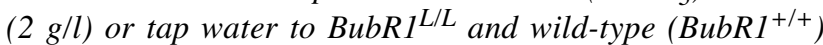
mice for 16 weeks and examined the subsequent incidence of tumours. Results: $\mathrm{KBrO}_{3}$-treated $\mathrm{BubR} 1^{\mathrm{L} / L}$ mice showed significantly higher mortality than the $\mathrm{KBrO}_{3}$-treated $B u b R 1^{+/+}$and control tap water-treated mice $(p=0.0082)$. Histopathological and immunohistochemical analyses revealed that the spleens of surviving BubR1L/L mice were occupied by non-B-, non-T-cells with high proliferative potential. Conclusion: Our results indicate that low BUBRI expression increases oxidative stress-induced mortality in mice, possibly caused by splenic neoplasms.
\end{abstract}

This article is freely accessible online.

Correspondence to: Yoshihiko Maehara, MD, Ph.D., FACS, Department of Surgery and Science, Graduate School of Medical Sciences, Kyushu University, 3-1-1 Maidashi, Higashi-ku, Fukuoka 812-8582, Japan. Tel: +81 926425466, Fax: +81 926425482, e-mail: maehara@surg2.med.kyushu-u.ac.jp and Takuya Matsumoto, MD, Ph.D., FACS, Department of Surgery and Science, Graduate School of Medical Sciences, Kyushu University, 3-1-1 Maidashi, Higashiku, Fukuoka 812-8582, Japan. Tel: +81 926425466, Fax: +81 926425482, e-mail: takum@surg2.med.kyushu-u.ac.jp

Key Words: Oxidative stress, aneuploidy, $\mathrm{KBrO}_{3}$, splenic neoplasms.
Budding uninhibited by benzimidazole-related 1 (BUBR1) is a core component of the spindle assembly checkpoint, which monitors whether or not sister chromatids are correctly separated during mitosis. Dysfunction of BUBR1 provokes chromosomal instability, thus leading to aneuploidy (1). Baker et al. generated mice with $B u b R 1$ gene mutation with various decreased expression levels of BubR1 due to combinations of wild-type, null, and hypomorphic BubRl alleles (2-4). The mice that were homogeneous for the hypomorphic allele showed an early onset of aging phenotypes, such as short lifespan, cachectic dwarfism, lordokyphosis, cataracts, loss of subcutaneous fat, impaired wound healing, and decreased vascular wall elasticity $(2,4)$. Chromosomal instability, such as aneuploidy, frequently occurred in the cells derived from hypomorphic BubRl mice, but few mice spontaneously died of cancer under normal conditions (2). Notably, Dai et al. reported that mice with the wild-type allele and null allele were susceptible to carcinogen-induced adenocarcinoma in the lungs and intestines (5), suggesting that aneuploidy caused by the decreased expression of BUBR 1 might enhance carcinogeninduced tumorigenesis in mammals.

We recently generated a new strain of hypomorphic $B u b R 1$ mice in which the expression of BUBR1 is reduced to $20 \%$ of the normal level. These low BUBR1-expressing mutant mice (termed $B u b R l^{\mathrm{L} / \mathrm{L}}$ mice) do not display apparent abnormalities, such as progeria, infertility, shortened lifespan, or structural anomaly in the tissue during growth and development, under normal conditions. Therefore, $B u b R l^{\mathrm{L} / \mathrm{L}}$ mice are particularly suitable for investigating the precise roles of BUBR1 in age-related diseases, including cancer. Using these mice, we previously demonstrated that decreased expression of BUBR1 completely inhibits intimal hyperplasia after carotid ligation by suppressing the 
proliferation of vascular smooth muscle cells (6). We also demonstrated that $B u b R 1^{\mathrm{L} / \mathrm{L}}$ mice show a delayed liver regeneration after partial hepatectomy because of intercalated disc abnormality associated with increased hepatocyte necrosis and the reduced expression of desmocollin-1 (7).

BUBR1 is involved in cell proliferation and DNA aneuploidy through stimulation of reactive oxygen species (ROS). Guntani et al. revealed that aging-related loss of BUBR1 and subsequent increases of ROS affect the reduction of proliferative capacity of aged smooth muscle cells (8). The expression of BUBR 1 and the proliferative capacity of aged human aortic smooth muscle cells (hAoSMC) was reduced with a progression of passages. No such phenomena were observed in young hAoSMC. The production of ROS induced by angiotensin II was also higher in aged hAoSMC than in younger cells. Moreover, downregulation of BubRl via RNA interference reduced the proliferative activity and increased the ROS production in hAoSMC. These results strongly suggest that BUBR1 is involved in the proliferative potential and ROS production in these cells (8). Ikawa-Yoshida et al. demonstrated that BUBR 1 contributes to oxidative stress-induced aneuploidy in p53-deficient cells (9). Oxidative stress activated the p53 signaling pathway and down-regulated both BubRl and mitotic arrest deficient 2 (Mad2) expression in a p53dependent. In cells made p53-deficient via RNA interference, treatment with potassium bromate $\left(\mathrm{KBrO}_{3}\right)$ caused an increase of polyploidy and bi-nucleated cells. However, when the expressions of $p 53$ and $B u b R l$ were knocked-down simultaneously, there was not an increase in polyploidy or bi-nucleated cells (9). These results suggest that p53 might play a critical role in the suppression of oxidative stressinitiated mitotic errors through the down-regulation of spindle assembly check point factors. Additionally, cells lacking p53 function might have an increased ability to reenter the cell cycle and initiate DNA replication even in cells with incorrect chromosomal numbers. Because insufficient BUBR1 leads to the inactivation of spindle assembly check point, resulting in an increased incidence of DNA aneuploidy (2), the co-down-regulation of $p 53$ and $B u b R l$ was expected to encourage an increase in polyploidy. However, contrary to this expectation, BubRl down-regulation suppressed the emergence of polyploid cells that is caused by oxidative stress when p53 alone is suppressed. Although the underlying mechanism is unclear, these results suggest that other BUBR1 functions, such as its relationship to the p16 ${ }^{\mathrm{INK} 4 \mathrm{~A}}-\mathrm{Rb}$ signaling pathway, the ubiquitin-mediated proteasomal degradation of cell-division cycle protein 20 (CDC20) in the $\mathrm{G}_{0}$ phase, and the maintenance of anaphasepromoting complex/ cyclosome CDC20 homolog 1 activity, might contribute to the observed phenotypes (9).

ROS are inevitably produced in cells during the processes of aerobic metabolism, signaling, and biophylaxis. Formation of ROS is further enhanced by exogenous stimuli, such as ionizing radiation, ultraviolet light, and various chemical mutagens. ROS attack DNA, and the resulting DNA oxidation then causes either spontaneous mutagenesis or cell death, which is implicated in various age-related diseases, such as cancer and neurodegeneration. Among the various types of oxidative DNA damage, 8-oxoguanine (8-oxoG) is highly mutagenic. During DNA replication, 8-oxoG can form a pair with adenine or cytosine, thus causing a mutation in the next round of replication $(10,11)$. An oxidizing reagent, $\mathrm{KBrO}_{3}$, which is used as a food additive for wheat flour, is known to induce 8-oxoG in the genomes of rats and mice $(12,13)$. $\mathrm{KBrO}_{3}$ has also been recognized as a renal carcinogen in rats $(14,15)$. In mammals, three enzymes, mutT homolog 1 (MTH1), 8-oxoguanine glycosylase 1 (OGG1), and mutY DNA glycosylase (MUTYH), play important roles in preventing 8-oxoG-related mutagenesis (10). MTH1 hydrolyses 8-oxo-dGTP to its monophosphate form and pyrophosphates, thereby preventing the incorporation of the mutagenic substrate into DNA during replication. OGG1, an 8-oxoG DNA glycosylase, excises 8-oxoGs opposite cytosines in DNA, which minimizes the formation of the premutagenic base pair, A:8-oxoG. MUTYH is a DNA glycosylase that excises adenines incorporated opposite 8oxoG. Defects of these enzymes lead to an increased tumor incidence in mice and humans.

We previously developed an experimental system for oxidative DNA damage-induced tumorigenesis in the small intestine of mice (16). We showed that chronic oxidative stress experimentally induced by $\mathrm{KBrO}_{3}$ resulted in multiple tumour formation in the small intestines of Mutyh-null mice $(16,17)$. We also reported that mismatch repair-deficient mice show a susceptibility to $\mathrm{KBrO}_{3}$-induced intestinal carcinogenesis (18). In order to examine the effects of oxidative stress on mice with BUBR1 insufficiency, we performed similar $\mathrm{KBrO}_{3}$-induced tumorigenesis experiments using $B u b R 1^{\mathrm{L} / \mathrm{L}}$ mice.

\section{Materials and Methods}

Experimental animals. Low-BUBR1-expressing mutant $\left(B u b R l^{\mathrm{L} / \mathrm{L}}\right)$ and wild-type (WT) littermates $\left(B u b R 1^{+/+}\right)$with a mixed genetic background of $\mathrm{C} 57 \mathrm{BL} / 6 \mathrm{~J}$ and $129 / \mathrm{SvJ}$ were generated in our laboratory as previously described (5). $\mathrm{KBrO}_{3}$-induced tumorigenesis experiments were performed using 6- to 8-week-old $B u b R l^{\mathrm{L} / \mathrm{L}}$ and $B u b R 1^{+/+}$mice. Mice with each genotype were divided into two groups: the control group and a group treated with $\mathrm{KBrO}_{3}$ (2 g/l; Nacalai Tesque, Kyoto, Japan) via drinking water. The dose of $\mathrm{KBrO}_{3}$ was selected on the basis of previous studies so as to be toxic without lethal effects $(16,18)$. At the end of the experimental period of 16 weeks, the mice were sacrificed by cervical decapitation. Blood and urine were collected and kept at $4^{\circ} \mathrm{C}$ for biochemical analyses, testes were frozen for use in western blotting, and spleens were fixed with formalin and embedded in paraffin for histopathological examination. The animals were treated 
according to the Guidelines for the Care and Use of Laboratory Animals of Kyushu University (Approval no. A28-153-0).

Quantitative analysis of urine 8-oxo-2'-deoxyguanosine (8-OHdG). To assess the level of oxidative stress, urinary $8-\mathrm{OHdG}$ was measured. Urine collected from $B u b R I^{\mathrm{L} / \mathrm{L}}$ and $B u b R 1^{+/+}$mice after administration of $\mathrm{KBrO}_{3}$ or tap water was used in these tests. 8OHdG was detected by performing New 8-OHdG check ELISAs (Nikken SEIL, Fukuroi, Japan) according to the manufacturer's instructions. 8-OHdG was standardized to urine creatinine levels, which were measured by LabAssay Creatinine (Wako Pure Chemical Industries, Osaka, Japan).

Cell culture. In order to compare the proliferative ability and sensitivity to the toxic effect of $\mathrm{KBrO}_{3}$, hematopoietic cells were obtained from femoral bone marrow of untreated $B u b R l^{\mathrm{L} / \mathrm{L}}$ and $B u b R 1^{+/+}$mice. The hematopoietic progenitor cells were collected by using an EasySep Mouse Hematopoietic Progenitor Cell Enrichment Kit (STEMCELL Technology Inc., Vancouver, B.C. Canada) according to the manufacturer's instructions. Collected progenitor cells were counted and cultured at a density of $2 \times 10^{5} / \mathrm{ml}$ in RPMI- 1640 (Wako Pure Chemical Industries) with $10 \%$ heat-inactivated fetal bovine serum (Sigma-Aldrich Corp, St. Louis, MO, USA), 100 U/ml penicillin and $100 \mu \mathrm{g} / \mathrm{ml}$ streptomycin (Thermo Fisher Scientific Inc., Waltham, MA, USA) in low-cell-binding plastic disposable tissue culture 24-well dishes at $37^{\circ} \mathrm{C}$ in a $5 \% \mathrm{CO}_{2} / 95 \%$ air incubator. Cells were treated with or without $10 \mathrm{mM} \mathrm{KBrO}_{3}$. Cultured cells were washed with phosphate-buffered saline and harvested with $1 \mathrm{ml}$ of $0.05 \%$ trypsin-EDTA solution (Thermo Fisher Scientific Inc.) and counted when cells became subconfluent $(n=3)$.

Immunohistochemistry. Formalin-fixed, paraffin-embedded tissue specimens were used for immunohistochemical analysis. Samples were de-paraffinised in xylene, rehydrated with graded ethanol, and washed in distilled water. The sections were pre-treated for $20 \mathrm{~min}$ at $120^{\circ} \mathrm{C}$ in $0.01 \mathrm{M}$ citrate buffer, $\mathrm{pH} 6.0$, for antigen retrieval. After a blocking procedure with $3 \%$ skim milk at room temperature for $10 \mathrm{~min}$, the sections were incubated with a primary antibody against cluster of differentiation 3 (CD3) (rabbit polyclonal, ab5690; 1:100; Abcam, Cambridge, UK), cluster of differentiation 45R (CD45R) (rat monoclonal, ab64100; 1:100; Abcam), myeloperoxidase (MPO) (rabbit polyclonal, ab139748; 1:1000; Abcam), cluster of differentiation 34 (CD34) (rabbit monoclonal, ab81289; 1:2500; Abcam), cluster of differentiation 56 (CD56) (rabbit polyclonal, ab95153; 1:500; Abcam), or Ki-67 (rabbit monoclonal, \#12202; 1:400; Cell Signaling Technology, Danvers, MA, USA) in a humidifying chamber at $4^{\circ} \mathrm{C}$ overnight. Endogenous peroxidase activity was blocked by incubating tissue sections in $0.3 \% \mathrm{H} 2 \mathrm{O} 2$. After incubation with an horse radish peroxidase-conjugated secondary antibody, the signals were visualized using 3,3'diaminobenzidine.

Biochemical analyses. Plasma levels of blood urea nitrogen (BUN), creatinine $(\mathrm{Cr})$, asparate:2-oxoglutarate aminotransferase (AST) and alanine:2-oxoglutarate aminotransferase (ALT) were analyzed by Nagashima Life Sciences Laboratory (Shiga, Japan).

Protein preparation and western blot analysis. Mouse testes were minced, and the proteins were extracted with CelLytic MT Cell Lysis Reagent (Sigma-Aldrich) supplemented with Halt Protease Inhibitor
Cocktail 100x (Thermo Fisher Scientific) according to the manufacturer's instructions. The protein concentration was determined using the Pierce BCA Protein Assay Kit (Thermo Fisher Scientific) according to the manufacturer's instructions. The blots were probed with a primary antibody for BUBR1 (NBP1-19555; 1:1000; Nobus Biological, Littleton, CO, USA). Equal loading was confirmed using an antibody against tubulin (ab4074; $1 \mu \mathrm{g} / \mathrm{ml}$; Abcam).

Statistical analysis. Data are presented as the means \pm standard error (SE). The Student's $t$-test and the log-rank test were used where appropriate with JMP pro (version 11.0.0; SAS Institute Inc., Cary, NC, USA). Significance was assumed at $p<0.05$.

\section{Results}

$B u b R I^{L / L}$ and $\mathrm{BubRI}^{+/+}$mice suffer equally from $\mathrm{KBrO}_{3}$ induced oxidative stress. In order to compare the effects of $\mathrm{KBrO}_{3}$-induced oxidative stress on mice with low or normal levels of BUBR1, we prepared seven $B u b R l^{\mathrm{L} / \mathrm{L}}$ and 10 $B u b R I^{+/+}$mice with similar body weights $(20.0 \pm 1.5 \mathrm{vs}$. $20.9 \pm 0.4$, respectively; $p=0.47$ ) for the experiments. The insufficiency of BUBR 1 in $B u b R I^{\mathrm{L} / \mathrm{L}}$ mice was confirmed by western blotting assays (Figure 1a). According to the chronological body weights of surviving mice, both $B u b R I^{\mathrm{L} / \mathrm{L}}$ and $B u b R I^{+/+}$mice given $\mathrm{KBrO}_{3}$ gradually lost weight (Figure 1b). There were no significant differences in weight loss between the two groups treated with $\mathrm{KBrO}_{3}$.

Urinary $8-\mathrm{OHdG}$ is a marker for oxidative stress, therefore after administration of $\mathrm{KBrO}_{3}$, urine was collected and 8OHdG levels were measured. The amounts of 8-OHdG were normalized using urine creatinine content. Urine 8-OHdG was elevated by the administration of $\mathrm{KBrO}_{3}$, but the levels of urine 8-OHdG were not significantly different in $B u b R I^{\mathrm{L} / \mathrm{L}}$ and $B u b R I^{+/+}$mice following $\mathrm{KBrO}_{3}$ treatment (Figure 1c). These results indicate that $B u b R l^{\mathrm{L} / \mathrm{L}}$ and $B u b R I^{+/+}$mice suffered equally from the effects of oxidation caused by $\mathrm{KBrO}_{3}$.

The administration of $\mathrm{KBrO}_{3}$ increases the mortality of $B u b R 1^{L / L}$ mice. Over the period of the 16-week administration of $\mathrm{KBrO}_{3}$, the mortality rate of $B u b R 1^{\mathrm{L} / \mathrm{L}}$ mice was significantly higher than that of BubR $1+/+$ mice (Kaplan-Meier analysis; $p<0.05$ ) (Figure 2a). Three $B u b R I^{\mathrm{L} / \mathrm{L}}$ mice died in the early phase (in the first eight weeks) and two died in the second eight-week period, while only one $\mathrm{BubRI}^{+/+}$mouse died over the entire period. During necropsy of these mice, we observed dark red intestinal fluids suggestive of gastrointestinal hemorrhage in the two mice that died in the later phase but saw no apparent lesions in the three $B u b R I^{\mathrm{L} / \mathrm{L}}$ mice that died in the early phase (Figure 2b). None of the mice given tap water in either the BubR $1^{\mathrm{L} / \mathrm{L}}$ or $B u b R 1^{+/+}$groups died during the entire period.

Surviving BubRIL/L mice exhibited an elevated BUN level. After the administration of $\mathrm{KBrO}_{3}$, blood was collected from 


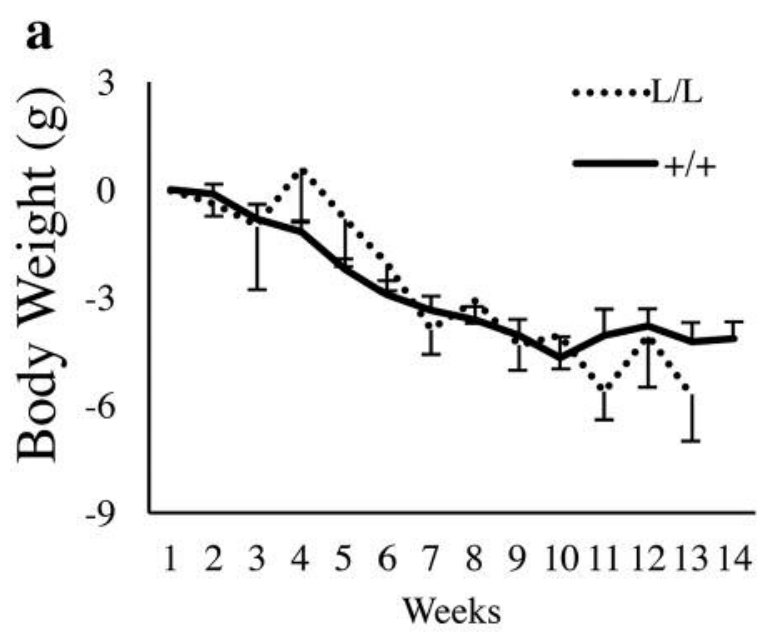

b

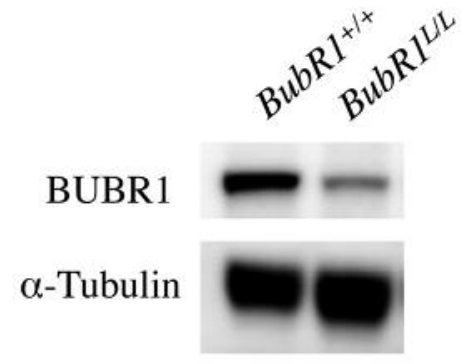

c

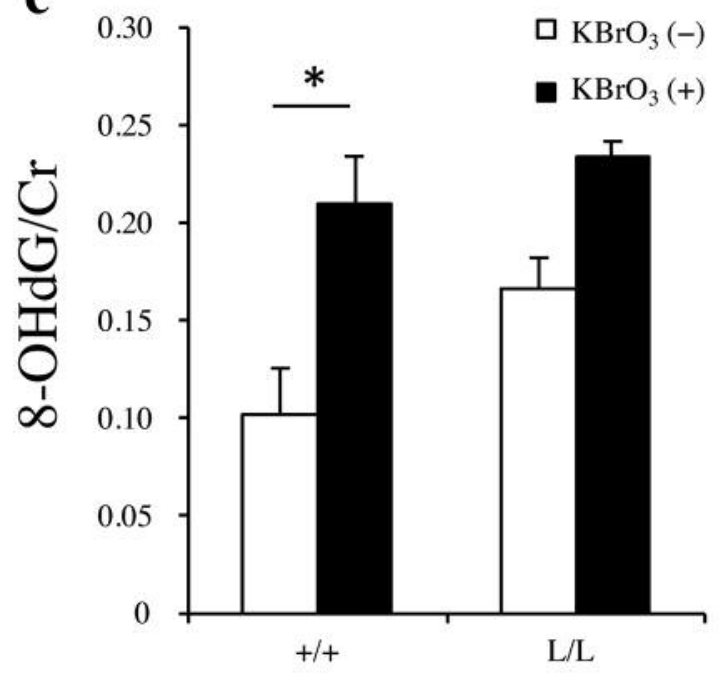

Figure 1. Oxidative damage induced by $\mathrm{KBrO}_{3}$ in $\mathrm{BubR1^{L/L }}$ and BubRI $1^{+/+}$mice. BubRI $1^{L / L}(L / L)$ and BubRI $1^{+++}(+/+)$mice were left untreated $\left[\mathrm{KBrO}_{3}(-)\right]$ or treated with $\mathrm{KBrO}_{3}\left[\mathrm{KBrO}_{3}(+)\right]$. a: The weekly change in body weight of BubR1L/L $(L / L)$ and BubR1+/+ (+/+) mice over 14 weeks of treatment with $\mathrm{KBrO}_{3}$. There was no significant difference in the changes of body weight between these two groups. $b$ : The expression of BUBR1 in testes from untreated BubR1 L/L and BubR1 $1^{++}$mice as assessed by western blot; $\alpha$-tubulin expression was included as a control. c: Levels of 8-oxo-2'-deoxyguanosine (8-OHdG) in urine standardized by creatinine level. There was no significant

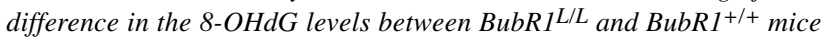
following $\mathrm{KBrO}_{3}$ treatment. *Significantly different at $p<0.05$. the surviving mice, and biochemical analyses of the blood were performed. The results show that the surviving $\mathrm{KBrO}_{3}$ treated $B u b R I^{\mathrm{L} / \mathrm{L}}$ mice had a significantly increased level of BUN compared with the untreated mice, but AST and ALT levels were not significantly elevated by $\mathrm{KBrO}_{3}$ treatment (Figure 2c). No increase in the BUN level was observed in the $\mathrm{KBrO}_{3}$-treated $\mathrm{BubRI^{+/+ }}$ mice. There was no difference in the creatinine levels between the animals with and without $\mathrm{KBrO}_{3}$ treatment in either genotype group. These results suggest that the $\mathrm{KBrO}_{3}$-treated $\mathrm{BubR} l^{\mathrm{L} / \mathrm{L}}$ mice suffered from dehydration.

Non-B-, non-T-cells occupied the spleens of BubR1 $1^{L / L}$ mice treated with $\mathrm{KBrO}_{3}$. In order to investigate the effects of $\mathrm{KBrO}_{3}$ on the mice in more detail, the surviving mice were euthanized and dissected. An intestinal tumor with a 1-mm diameter was detected in one $B u b R I^{+/+}$mouse, but no such tumors were observed in $B u b R l^{\mathrm{L} / \mathrm{L}}$ mice. However, splenomegaly was identified in two of the surviving $B u b R 1^{\mathrm{L} / \mathrm{L}}$ mice, while such lesions were not observed in $B u b R 1^{+/+}$mice. The inspection of spleens stained by hematoxylin-eosin revealed that the pulp boundary was unclear in the spleens from two surviving $B u b R l^{\mathrm{L} / \mathrm{L}}$ mice. Additionally, many lymphocyte-like cells had gathered in the red pulp of these mice, suggestive of lymphoma or invasive leukemia (Figure 3a). There were no such lesions in the $B u b R 1^{+/+}$or $B u b R 1^{\mathrm{L} / \mathrm{L}}$ mice that were treated with tap water.

In order to identify the lineage of these cells, immunohistochemistry was performed. The cells did not express the B-lymphocyte marker CD45R nor the Tlymphocyte marker CD3. Moreover, the expressions of MPO, CD34, and CD56 were also negative. A subset of the cells was positive for Ki-67 expression (Figure 3b). These findings suggest that the cells might be non-B-, non-T-cell neoplasms with a high proliferative potential.

Sensitivity to oxidative stress was high in BubR $1^{L / L}$ mouse progenitor cells. The findings of splenic neoplasms similar to stem cell lymphoma prompted us to examine the proliferative potential of the hematopoietic progenitor cells derived from $B u b R l^{\mathrm{L} / \mathrm{L}}$ mice as well as the effect of oxidative stress on these cells. The proliferative potential of the $B u b R l^{\mathrm{L} / \mathrm{L}}$ progenitor cells was significantly lower than that of the $B u b R I^{+/+}$cells. The proliferative potential of the progenitor cells decreased following treatment with $10 \mu \mathrm{M}$ $\mathrm{KBrO}_{3}$. This effect was more profound in the $B u b R l^{\mathrm{L} / \mathrm{L}}$ progenitor cells than it was in the $B u b R I^{+/+}$cells (Figure 4).

\section{Discussion}

Here, we reveal that $B u b R 1^{\mathrm{L} / \mathrm{L}}$ mice are hypersensitive to oxidative-stress compared to $B u b R 1^{+/+}$mice. Moreover, the cells with immunophenotypic profile of $\mathrm{CD}^{-}, \mathrm{CD}^{-} 5 \mathrm{R}^{-}$, 
$\mathbf{a}$
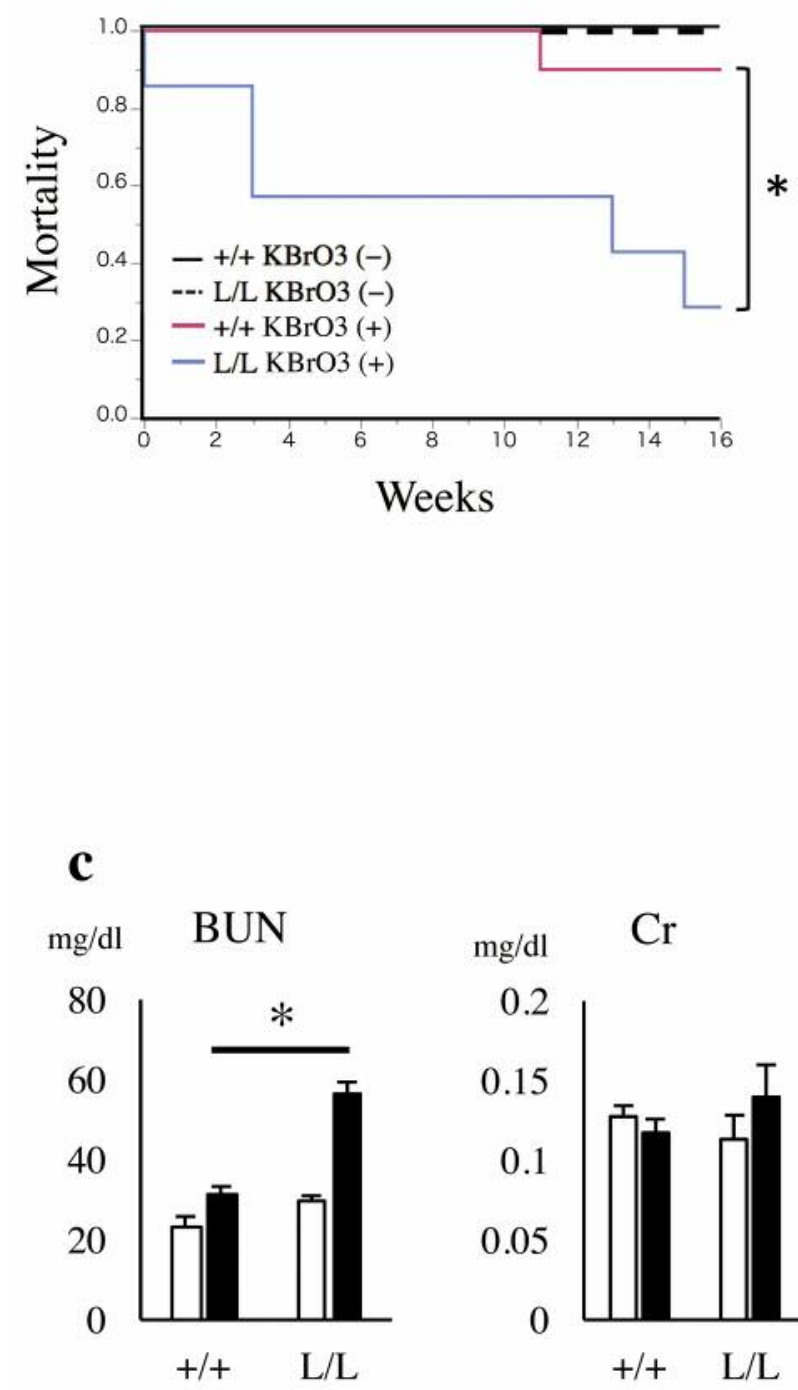
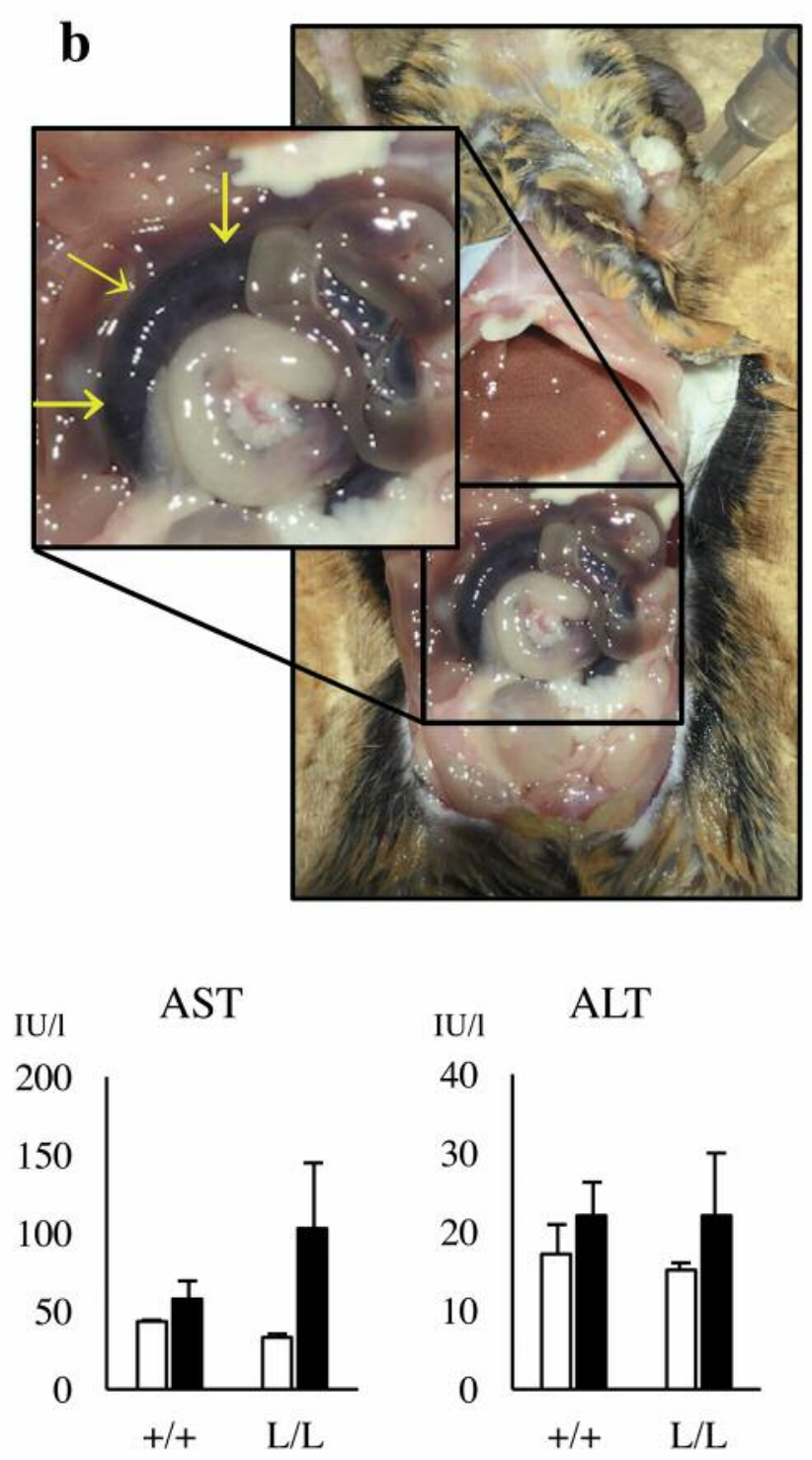

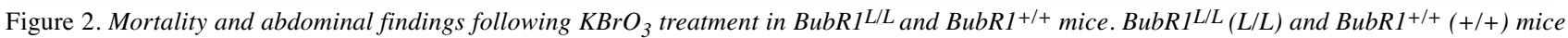
were left untreated $\left[\mathrm{KBrO}_{3}(-)\right]$ or treated with $\mathrm{KBrO}_{3}\left[\mathrm{KBrO}_{3}(+)\right]$. a: The mortality of these mice over 16 weeks was assessed. A Kaplan-Meier analysis was performed to determine the significance of the differences between these groups $\left[+/+\mathrm{KBrO}_{3}(-): n=5,+/+\mathrm{KBrO} \mathrm{O}_{3}(+): n=5, L / L\right.$

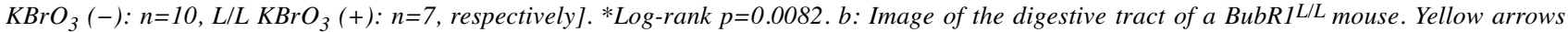
indicate hemorrhage. $c$ : The results of biochemical analysis of plasma levels of blood urea nitrogen (BUN), creatinine (Cr), asparate:2-oxoglutarate aminotransferase (AST), and alanine:2-oxoglutarate aminotransferase $(A L T)$. The open and filled bars indicate $\mathrm{KBrO}_{3}(-)$ and $\mathrm{KBrO} \mathrm{O}_{3}(+)$, respectively. ${ }^{*}$ Significantly different at $p<0.05$.

$\mathrm{MPO}^{-}, \mathrm{CD}^{-} 6^{-}$, and $\mathrm{CD} 34^{-}$occupied the spleens of surviving $B u b R I^{\mathrm{L} / \mathrm{L}}$, suggesting the development of stem cell lymphoma, a group of non-B-, non-T-cell neoplasms. Splenic neoplasms were recognized only in the $B u b R l^{\mathrm{L} / \mathrm{L}}$ mice treated with $\mathrm{KBrO}_{3}$. A single factor, either the insufficiency of BUBR1 or the administration of $\mathrm{KBrO}_{3}$, was unable to cause these phenomena, thus suggesting that the combination of low BUBR1 expression with increased oxidative stress may lead to a reduced tolerance to oxidative stress and the development of splenic lymphoma in mice.

$\mathrm{KBrO}_{3}$ is a well-known oxidizing agent which is used as a food additive. The toxicity of $\mathrm{KBrO}_{3}$ as a causative agent of oxidative stress has been well-studied (19). Here, the dosage of $\mathrm{KBrO}_{3}$ was selected by referring to previous studies so as not to administer a lethal dose $(16,18,20,21)$. The dosage of $\mathrm{KBrO}_{3}$ per body weight was very similar between the two 

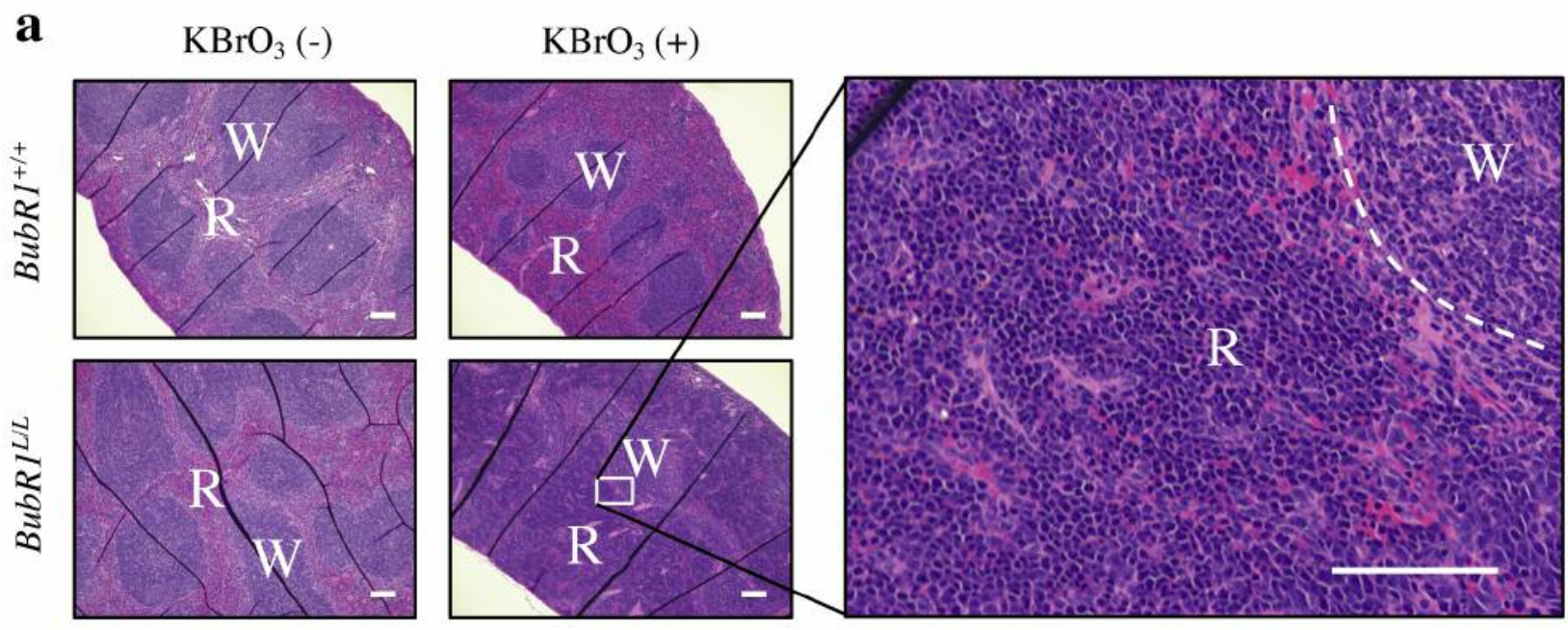

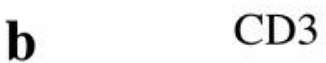

MPO
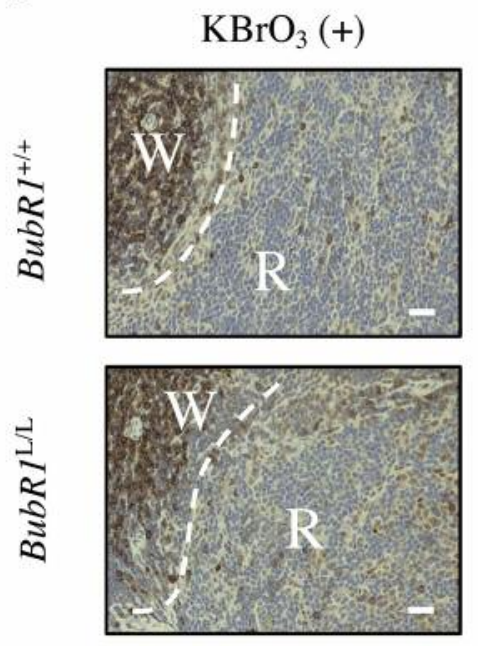

CD34
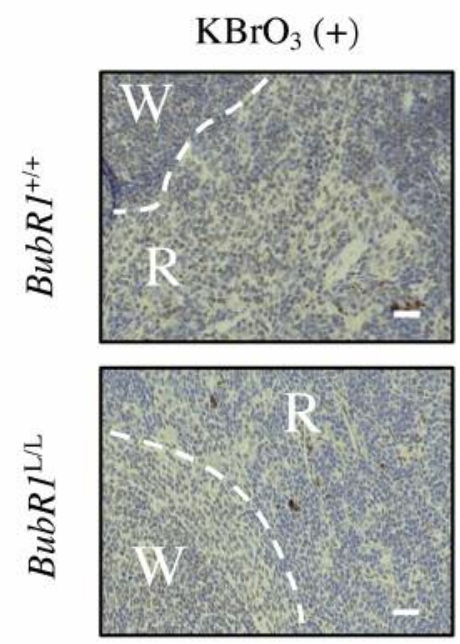

$\mathrm{KBrO}_{3}(+)$
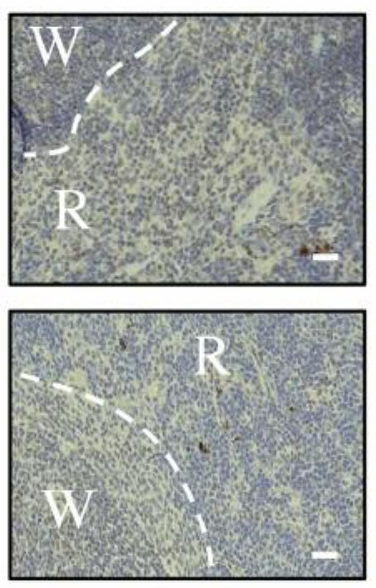

CD56
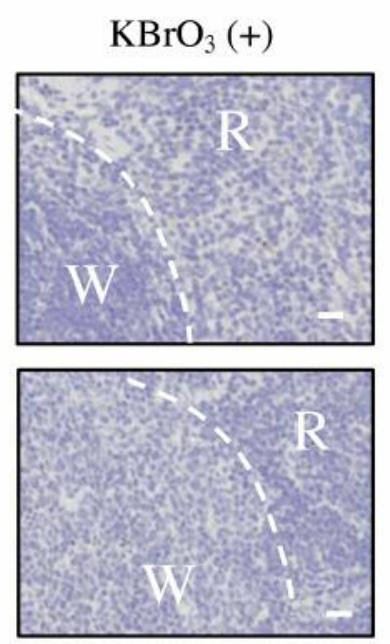

CD45R

$\mathrm{KBrO}_{3}(+)$
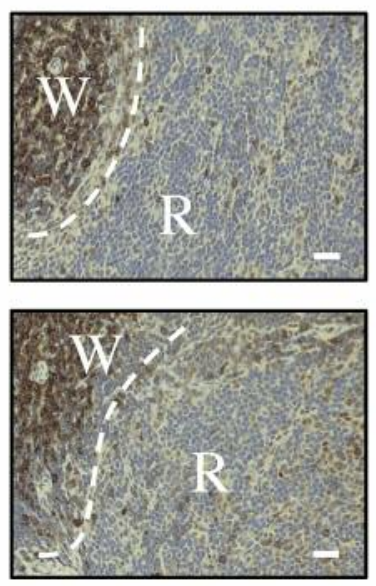

Ki-67

$\mathrm{KBrO}_{3}(+)$
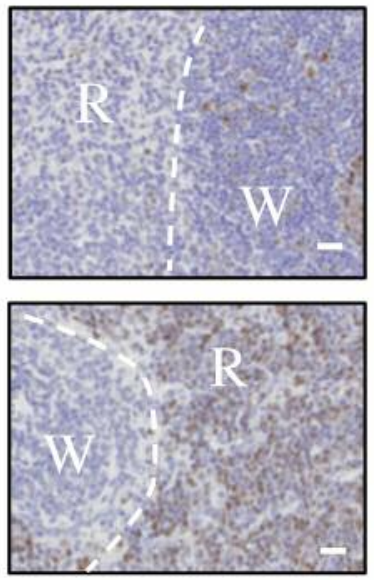

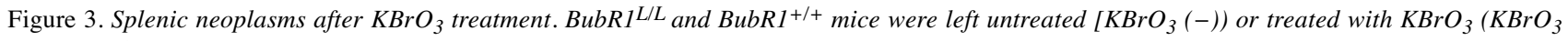
$(+)]$ for 16 weeks. Representative microscopy images of spleen sections stained with hematoxylin-eosin (a) and immunohistochemical staining of CD3, MPO, CD45R, CD34, CD56, and Ki-67 (b) are shown. Bars $=25 \mu \mathrm{m}$, W: white pulp, R: red pulp. 
groups because the $B u b R l^{\mathrm{L} / \mathrm{L}}$ and $B u b R I^{+/+}$mice had almost the same body weights before the administration of $\mathrm{KBrO}_{3}$. The similarity of the $\mathrm{KBrO}_{3}$ dosage per body weight is also supported by the finding that there was no significant difference between the amounts of $8-\mathrm{OHdG}$ in the urine from the two groups of $\mathrm{KBrO}_{3}$-treated mice (Figure 1C). Despite undergoing equivalent levels of oxidative stress and resulting DNA damage, $B u b R l^{\mathrm{L} / \mathrm{L}}$ mice had an extremely high mortality rate during the $\mathrm{KBrO}_{3}$ treatment compared with $\mathrm{BubRl^{+/+ }}$ mice. It is possible that the poor proliferative potential of cells that is caused by BUBR1 insufficiency might lead to a reduced tolerance to oxidative stress in mice.

In this study, $\mathrm{KBrO}_{3}$-treated $B u b R l^{\mathrm{L} / \mathrm{L}}$ mice had a high mortality rate. In order to investigate the cause of death in these mice, necropsies were performed on all the mice that died during the experiment. However, most of the mice did not exhibit any specific features indicating the cause of death, such as tumorigenesis. The results of biochemical analyses of the surviving $B u b R l^{\mathrm{L} / \mathrm{L}}$ mice and necropsies of the non-survivors suggest that the clinical cause of death in the $B u b R 1^{\mathrm{L} / \mathrm{L}}$ mice was probably dehydration or gastrointestinal hemorrhage. The decline in cell proliferation due to BUBR1 insufficiency is likely one of the reasons that the $B u b R l^{\mathrm{L} / \mathrm{L}}$ mice had a high mortality following $\mathrm{KBrO}_{3}$ treatment. The $\mathrm{BubRI}^{+/+}$mice were able to recover from the damage induced by $\mathrm{KBrO}_{3}$, while the $B u b R 1^{\mathrm{L} / \mathrm{L}}$ mice were unable to overcome the toxicity of $\mathrm{KBrO}_{3}$ because their lower proliferative capacity limited their recuperative abilities. The accumulated and unhealed damage induced by $\mathrm{KBrO}_{3}$ injured the intestinal mucosa and might have resulted in the malabsorption of water and gastrointestinal hemorrhage.

In contrast, when the surviving $B u b R l^{\mathrm{L} / \mathrm{L}}$ mice were sacrificed, the necropsies performed on these animals showed that their spleens were occupied by non-B-, non-T-cells with a high proliferative potential, similar to that of leukemia or lymphoma cells. Previous studies have shown that the oral ingestion of $\mathrm{KBrO}_{3}$ causes intestinal tumors in animals with impaired DNA repair (16), and Dai et al. reported that $B u b R 1^{+/-}$mice are susceptible to carcinogen-induced adenocarcinoma (5). The causes of production of both the splenic neoplasms and other tumors are unclear. The thresholds of BUBR1 expression level for tumorigenesis might differ among tissues. It is probable that tumorigenesis occurred when the combination of the point mutations induced by $\mathrm{KBrO}_{3}$ and chromosomal instabilities, such as aneuploidy, which are induced by the insufficiency of BUBR1 exceeded the tolerance threshold. The profile of cellsurface and proliferation markers that we observed suggests that the cells that appeared in the spleen were similar to leukemia cells. Notably, the immunophenotype of these cells indicates the they are likely to be immature cells, such as in stem cell leukemia, because most cells did not express the lymphocytic cell surface markers CD3 and CD45R (22).

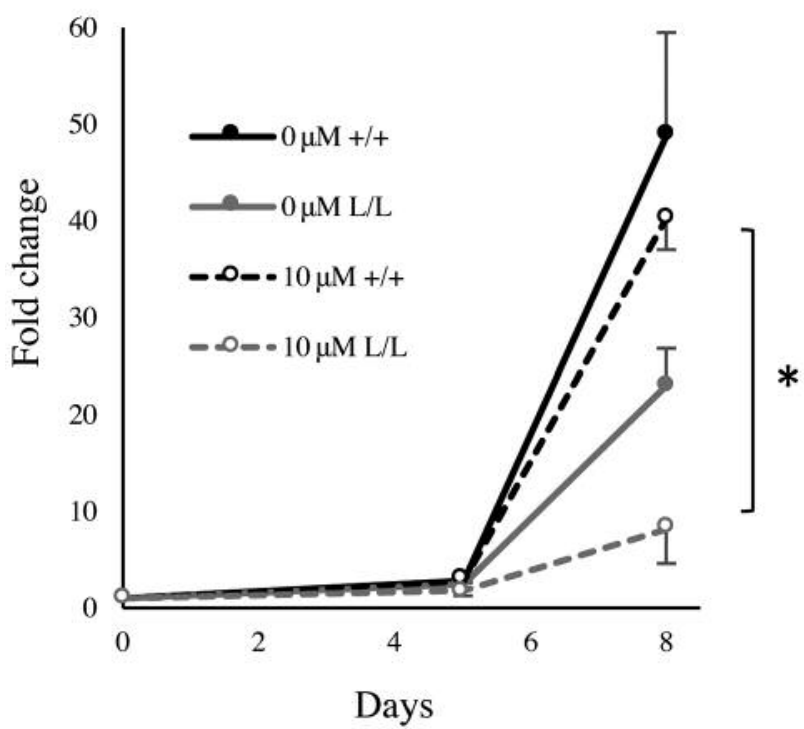

Figure 4. The proliferation of hematopoietic stem cells. Hematopoietic

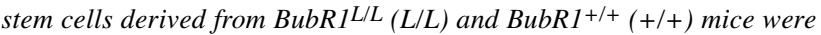
cultured with interleukin-3 and -6, fms-like tyrosine kinase 3, and stem cell factor in the absence $(0 \mu \mathrm{M})$ or presence $(10 \mu \mathrm{M})$ of $\mathrm{KBrO}_{3}$, and then counted at days 5 and 8 . *Significantly different at $p<0.05$.

There are few reports indicating the direct relationship between the BUBR1 expression and leukemia. Dominik et $a l$. identified that a low expression of BUBR1 affected the sensitivity to antimitotic therapy of many acute myeloid leukemia cell lines (23). However, the relationship between the expression level of BUBR1 and the occurrence of leukemia remains unclear. It is well-known that a genetic defect plays a role in leukemia. Micronuclei are a hallmark of DNA damage and markers of exposure to genotoxic agents (24). Using $B u b R I^{+/-}$and wild-type mouse embryonic fibroblasts cells, Dai et al. showed that the number of micronuclei was greatly increased in the low BUBR1 condition (5). $\mathrm{KBrO}_{3}$ also causes micronuclei in a dosedependent manner (25). These double stimulations, such as chromosomal instability and genotoxicity, might accelerate the accumulation of DNA damage. Recently, one study reported that such accumulation of massive DNA damage in micronuclei may cause chromothripsis to occur (24). Chromothripsis explains massive local DNA fragmentation producing complex rearrangements restricted to only one or a few chromosomes. This phenomenon could be one possible mechanism of tumorigenesis.

In summary, mice with BUBR1 insufficiency show hypersensitivity to oxidative stress. The combination of BUBR1 insufficiency and administration of $\mathrm{KBrO}_{3}$ worsens the proliferative capacity compared with the impaired proliferation induced by BUBR1 insufficiency alone; thus, this may lead to a reduced tolerance to oxidative stress. Treatment 
with $\mathrm{KBrO}_{3}$ resulted to high mortality in $B u b R l^{\mathrm{L} / \mathrm{L}}$ mice, possibly due to dehydration or gastrointestinal hemorrhage. Furthermore, the combination of BUBR1 insufficiency and $\mathrm{KBrO}_{3}$ treatment also produced non-B- and non-T-cell splenic tumours. This work provides new insights into the role of BUBR1 in oxidative stress, which may explain one mechanism of hypersensitivity to oxidative stress.

\section{Conflicts of Interest}

None of the Authors have any conflicts of interest in regard to this study.

\section{References}

1 Kapanidou M, Lee S and Bolanos-Garcia VM: BUBR1 kinase: protection against aneuploidy and premature aging. Trends Mol Med 21: 364-372, 2015.

2 Baker DJ, Jeganathan KB, Cameron JD, Thompson M, Juneja S, Kopecka A, Kumar R, Jenkins RB, de Groen PC, Roche P and van Deursen JM: BUBR1 insufficiency causes early onset of aging-associated phenotypes and infertility in mice. Nat Genet 36: 744-749, 2004.

3 Baker DJ, Wijshake T, Tchkonia T, LeBrasseur NK, Childs BG, van de Sluis B, Kirkland JL and van Deursen JM: Clearance of p16 ${ }^{\mathrm{INK} 4 \mathrm{~A}}$-positive senescent cells delays ageing-associated disorders. Nature 479: 232-236, 2011.

4 Matsumoto T, Baker DJ, d'Uscio LV, Mozammel G, Katusic ZS and van Deursen JM: Aging-associated vascular phenotype in mutant mice with low levels of BUBR1. Stroke 38: 1050-1056, 2007.

5 Dai W, Wang Q, Liu T, Swamy M, Fang Y, Xie S, Mahmood R, Yang YM, Xu M and Rao CV: Slippage of mitotic arrest and enhanced tumor development in mice with BubRl Haploinsufficiency. Cancer Res 64: 440-445, 2004.

6 Kyuragi R, Matsumoto T, Harada Y, Saito S, Onimaru M, Nakatsu Y, Tsuzuki T, Nomura M, Yonemitsu Y and Maehara Y: BUBR1 insufficiency inhibits neointimal hyperplasia through impaired vascular smooth muscle cell proliferation in mice. Arterioscler ThrombVasc Biol 35: 341-347, 2015.

7 Ikawa-Yoshida A, Matsumoto T, Okano S, Aoyagi Y, Matsubara Y, Furuyama T, Nakatsu Y, Tsuzuki T, Onimaru M, Ohkusa T, Nomura $\mathrm{M}$ and Maehara Y: BUBR1 Insufficiency impairs liver regeneration in aged mice after hepatectomy through intercalated disc abnormality. Sci Rep 6: 32399, 2016.

8 Guntani A, Matsumoto T, Kyuragi R, Iwasa K, Onohara T, Itoh H, Katusic ZS and Maehara Y: Reduced proliferation of aged human vascular smooth muscle cells - role of oxygen-derived free radicals and BUBR1 expression. J Surg Res 170: 143-149, 2011.

9 Ikawa-Yoshida A, Ando K, Oki E, Saeki H, Kumashiro R, Taketani K, Ida S, Tokunaga E, Kitao H, Morita M and Maehara Y: Contribution of BUBR1 to oxidative stress-induced aneuploidy in p53-deficient cells. Cancer Med 2: 447-456, 2013.

10 Tsuzuki T, Nakatsu Y and Nakabeppu Y: Significance of erroravoiding mechanisms for oxidative DNA damage in carcinogenesis. Cancer Sci 98: 465-470, 2007.

11 Nakabeppu Y, Sakumi K, Sakamoto K, Tsuchimoto D, Tsuzuki $\mathrm{T}$ and Nakatsu Y: Mutagenesis and carcinogenesis caused by the oxidation of nucleic acids. Biol Chem 387: 373-379, 2006.
12 Ballmaier D and Epe B: Oxidative DNA damage induced by potassium bromate under cell-free conditions and in mammalian cells. Carcinogenesis 16: 335-342, 1995.

13 Kasai H1, Nishimura S, Kurokawa Y and Hayashi Y: Oral administration of the renal carcinogen, potassium bromate, specifically produces 8-hydroxydeoxyguanosine in rat target organ DNA. Carcinogenesis 8: 1959-1961, 1987.

14 DeAngelo AB, George MH, Kilburn SR, Moore TM and Wolf DC: Carcinogenicity of potassium bromate administered in the drinking water to male $\mathrm{B} 6 \mathrm{C} 3 \mathrm{~F} 1$ mice and $\mathrm{F} 344 / \mathrm{N}$ rats. Toxicol Pathol 26: 587-594, 1998.

15 Kurokawa Y, Takayama S, Konishi Y, Hiasa Y, Asahina S, Takahashi M, Maekawa A and Hayashi Y. Long-term in vivo carcinogenicity tests of potassium bromate, sodium hypochlorite, and sodium chlorite conducted in Japan. Environ Health Perspect 69: 221-235, 1986.

16 Sakamoto K, Tominaga Y, Yamauchi K, Nakatsu Y, Sakumi K, Yoshiyama K, Egashira A, Kura S, Yao T, Tsuneyoshi M, Maki H, Nakabeppu Y and Tsuzuki T: Mutyh-null mice are susceptible to spontaneous and oxidative stress induced intestinal tumorigenesis. Cancer Res 67: 6599-6604, 2007.

17 Isoda T, Nakatsu Y, Yamauchi K, Piao J, Yao T, Honda H, Nakabeppu Y and Tsuzuki T: Abnormality in Wnt signaling is causatively associated with oxidative stress-induced intestinal tumorigenesis in MUTYH-null mice. Int J Biol Sci 10: 940-947, 2014.

18 Piao J, Nakatsu Y, Ohno M, Taguchi K and Tsuzuki T: Mismatch repair deficient mice show susceptibility to oxidative stressinduced intestinal carcinogenesis. Int J Biol Sci 10: 73-79, 2013.

19 Kurokawa Y, Maekawa A, Takahashi M and Hayashi Y: Toxicity and carcinogenicity of potassium bromate - a new renal carcinogen. Environ Health Persp 87: 309-335, 1990.

20 Arai T, Kelly VP, Minowa O, Noda T and Nishimura S: The study using wild-type and Oggl knockout mice exposed to potassium bromate shows no tumor induction despite an extensive accumulation of 8-hydroxyguanine in kidney DNA. Toxicol 221: 179-186, 2006.

21 Jaloszynski P, Murata S, Shinkai Y, Takahashi S, Kumagai Y, Nishimura $S$ and Yamamoto M: Dysfunction of NRF2 decreases $\mathrm{KBrO}_{3}$-induced oxidative DNA damage in Oggl-null mice. Biochem Biophys Res Commun 364: 966-971, 2007.

22 Karube K, Ohshima K, Tsuchiya T, Yamaguchi T, Suefuji H, Suzumiya J, Harada $M$ and Kikuchi M: Non-B, non-T neoplasms with lymphoblast morphology: further clarification and classification. Am J Surg Pathol 27: 1366-1374, 2003.

23 Schnerch D, Schmidts A, Follo M, Udi J, Felthaus J, Pfeifer D, Engelhardt $\mathrm{M}$ and Wäsch R: BUBR1 is frequently repressed in acute myeloid leukemia and its re-expression sensitizes cells to antimitotic therapy. Haematologica 98: 1886-1895, 2013.

24 Terradas M, Martín M and Genescà A: Impaired nuclear functions in micronuclei results in genome instability and chromothripsis. Arch Toxicol doi:10.1007/s00204-016-1818-4, 2016.

25 Awogi T, Murata K, Uejima M, Kuwahara T, Asanami S, Shimono $\mathrm{K}$ and Morita $\mathrm{T}$ : Induction of micronucleated reticulocytes by potassium bromate and potassium chromate in CD-1 male mice. Mutat Res 278: 181-185, 1992.

Received September 20, 2016 Revised October 6, 2016 Accepted October 10, 2016 